\title{
Finite Elements Modeling and Analysis of Double Skin Composite Plates
}

\author{
Mohamedien, A.R ${ }^{1}$, Omer, A.A ${ }^{2}$ \\ '(Civil Engineering Department, Military Technical College. / Cairo, Egypt.) \\ ${ }^{2}$ (Mechanical Engineering Department, Military Technical College / Cairo, Egypt.)
}

\begin{abstract}
Double skin composite (DSC) is a form of "steel/concrete/steel" sandwich structure; the steel plates are connected to a sandwiched concrete core with welded stud shear connectors. In the present paper, a finite element model for Double Skin Composite (DSC) panels subjected to quasi-static loading is developed. A series of quasi-static finite elements models are used to analyze deformation and energy absorption capacity of such system, when perforated by rigid penetrator with conical nose shape. Pilot test model is used to investigate the failure pattern in the composite panel. The obtained results are compared to the experimental results; good agreements are obtained between finite element and previous experimental results. Results show that such elements have great ability of absorbing energy when subjected to perforation due to ductility of lower plate skin and vertical stiffness of lower shear studs.
\end{abstract}

Keywords: Double skin composite; Quasi-static test; Shear connectors; Finite Elements.

\section{Introduction}

Double skin composite (DSC) construction is the term used to describe a structural system of steel plates connected to a sandwiched concrete core with welded stud shear connectors. The studs or bars are welded at both ends simultaneously. Manufactured units are taken to site, joined by welding, and filled with concrete. The bar/plate connections are subject to bar tension, bar shear, bar bending and plate tension. In 1986, the first proposed application of a steel/concrete/steel sandwich was for a submerged tube highway tunnel in North Wales [1-2]. The DSC structures are widely used for internal doors, and more recently in ships' steel partitions. The main problems that are facing the usage of reinforced concrete to resist impact loading that may cause penetration or perforation of slabs in buildings, shelters, and military buildings, are much smaller in ductility of concrete slabs. They need big slab thickness or great reinforcing steel ratio in slab section [3]. Yam and Chapman [4] studied the reduction in connector strength between push test values and those occurring in composite T-beams. They produced a plot of ultimate moment capacity for a composite T-beam against a connection ratio. This connection ratio was defined as the amount of connection provided divided by the amount of connection required to transfer the full connection force.

B. Mckinely, L.F Boswell [5], investigated the development of analytical solution for the elastic and plastic behavior of bi-steel with subsequent full-scale laboratory. These tests assumed that, in calculating the position of the neutral axis of a DSC panel, the concrete acting in tension has no strength. This assumption also ignores the bending stiffness of the plates about their own axes. In addition, the research investigated the failure mechanism of DSC panels.

Double composite (steel-concrete-steel) panels presented an excellent alternative solution of these problems due to its expected ductility. Previous finite element works were done dealing with such structures by N.E Shanmugam et al [6], who presented a finite element model for DSC slabs under static load with indirect representation of shear connectors in the model. M. Xie et al [7] investigated the shear behavior of frictionwelded bar-plate connections embedded in concrete to model a push-out test with direct representation of shear connectors by solid elements. The present paper develops a non-linear three-dimensional finite element model for Double Skin Composite (DSC) panels that are subjected to quasi-static loading using a general-purpose finite element package (ABAQUS). A series of quasi-static models are used to analyze deformation and energy absorption capacity of such system when perforated by rigid penetrator with conical nose shape. These models include variation of upper and lower plate thickness, increasing degree of shear interaction between upper or lower plates with concrete core, and reducing the distribution density of upper stud connectors with the same degree of interaction between upper steel skin and concrete core. The finite element and experimental results of a previous paper are compared [8]. Once the model verified the experimental program, it can be used in excessive study cases of different loads and measurements. There is a good agreement between finite element and experimental results. 


\section{Finite Element Modeling Scope}

The general purpose finite element code, ABAQUS, provides different types of elements for one- twoand three-dimensional problems such as plane stress, plane strain, three dimensional solid elements, straight, curved beams, and shell elements. ABAQUS/Explicit-Dynamic can be used efficiently to handle the problems of quasi-static loads. In order to avoid the effect of acceleration the amplitude function can be applied to load by smoothing the rate of loading. It also contains a suitable interaction set providing ability of various representations of interaction between model elements and allowing nodes of some elements to penetrate other elements' nodes by means of master and slave surfaces. Furthermore, it provides an algorithm of removing the failed elements due to penetration when reaching element ultimate strength.

\subsection{Finite Element Model of Double Skin Composite}

\subsubsection{Geometry; elements type, and meshing}

All panels are of dimensions $(1000 \mathrm{~mm} \times 1000 \mathrm{~mm})$, and have concrete core thickness of 50mm, except in the pilot panel; the concrete core was $80 \mathrm{~mm}$. All upper and lower studs used in the specimens have dimensions of $8 \mathrm{~mm}$ diameter of shank, and $12 \mathrm{~mm}$ diameter of stud head with $4 \mathrm{~mm}$ thickness of stud head. The total stud length is $35 \mathrm{~mm}$ except specimen (DSC5) which had upper studs' dimensions of $10 \mathrm{~mm}$ shank diameter, and $15 \mathrm{~mm}$ stud head diameter with $5 \mathrm{~mm}$ thickness. The same total stud length was used. Table (1) shows specifications of all specimens; while Figures (1), (2) show the dimensions, and stud distribution across the plates.

Table1. Specimens' details

\begin{tabular}{|c|c|c|c|c|c|c||}
\hline \multirow{2}{*}{ Specimen } & \multicolumn{3}{|c|}{ Top Plate } & \multicolumn{3}{c||}{ Bottom Plate } \\
\cline { 2 - 7 } & $\begin{array}{l}\text { Plate } \\
\text { thickness }\end{array}$ & $\begin{array}{l}\text { No. of } \\
\text { studs per } \\
\text { row }\end{array}$ & $\begin{array}{l}\text { Stud } \\
\text { spacing }\end{array}$ & $\begin{array}{l}\text { Plate } \\
\text { thickness }\end{array}$ & $\begin{array}{l}\text { No. of } \\
\text { studs per } \\
\text { row }\end{array}$ & $\begin{array}{l}\text { Stud } \\
\text { spacing }\end{array}$ \\
\hline Pilot test & $3 \mathrm{~mm}$ & 3 & $250 \mathrm{~mm}$ & $3 \mathrm{~mm}$ & 4 & $250 \mathrm{~mm}$ \\
\hline DSC1 & $4 \mathrm{~mm}$ & 3 & $150 \mathrm{~mm}$ & $2 \mathrm{~mm}$ & 3 & $150 \mathrm{~mm}$ \\
\hline DSC2 & $2 \mathrm{~mm}$ & 3 & $150 \mathrm{~mm}$ & $4 \mathrm{~mm}$ & 3 & $150 \mathrm{~mm}$ \\
\hline DSC3 & $2 \mathrm{~mm}$ & 7 & $150 \mathrm{~mm}$ & $2 \mathrm{~mm}$ & 3 & $150 \mathrm{~mm}$ \\
\hline DSC4 & $2 \mathrm{~mm}$ & 3 & $150 \mathrm{~mm}$ & $2 \mathrm{~mm}$ & 7 & $150 \mathrm{~mm}$ \\
\hline DSC5 & $2 \mathrm{~mm}$ & 5 & $150 \mathrm{~mm}$ & $2 \mathrm{~mm}$ & 3 & $150 \mathrm{~mm}$ \\
\hline
\end{tabular}

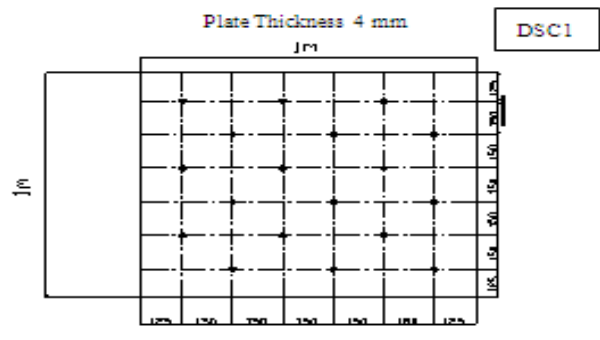

Bottom ptate

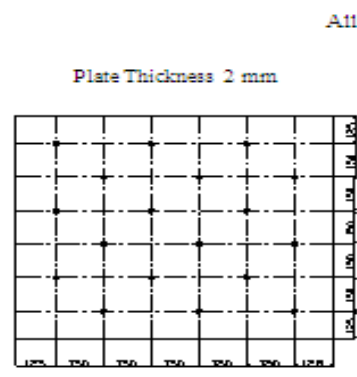

Bottom plats
Plate Thickness $2 \mathrm{~mm}$

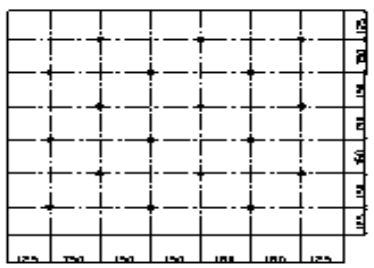

Upper plate

Plate Thickness $4 \mathrm{~mm}$

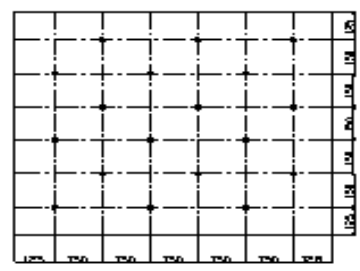

Upper plate

Fig.1. Dimensions and stud distribution across the plates DSC1 and DSC2 
Plate Thickness $2 \mathrm{~mm}$

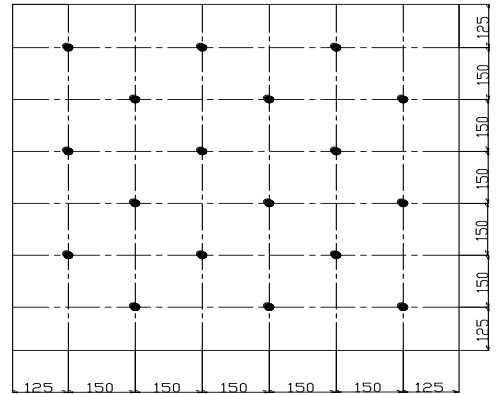

Bottom plate
DSC4

Plate Thickness $2 \mathrm{~mm}$

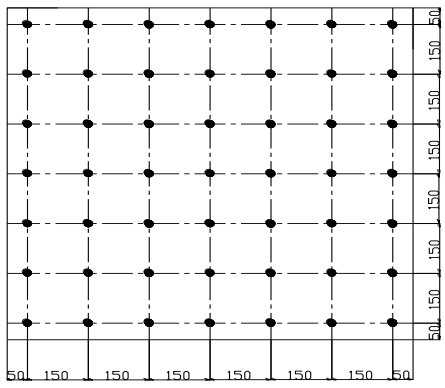

Bottom plate

Plate Thickness $2 \mathrm{~mm}$

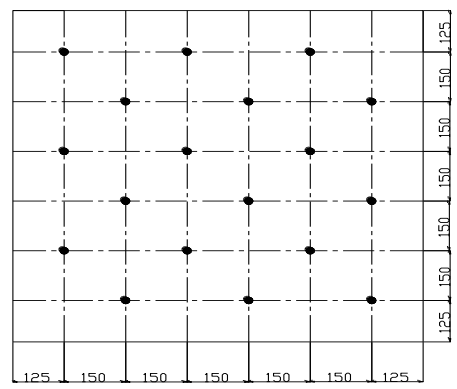

Bottom plate

DSC5
Plate Thickness $2 \mathrm{~mm}$

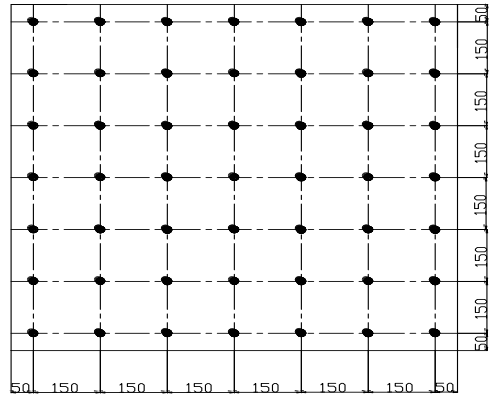

Upper plate

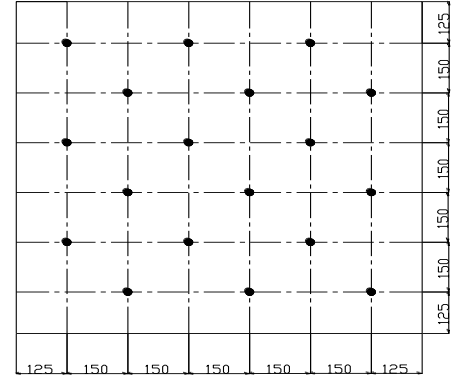

Upper plate

Plate Thickness $2 \mathrm{~mm}$

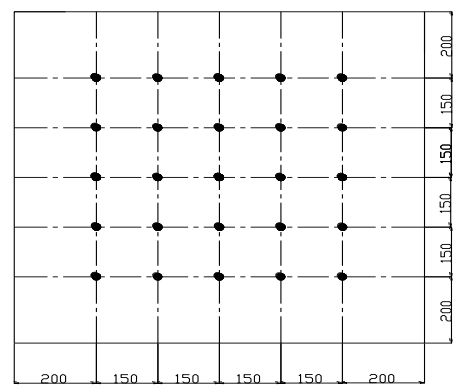

Upper plate

Fig.2. Dimensions and Stud distribution across the plates DSC3 to DSC5

The top and bottom steel plates of the DSC panels are modeled using four-nodes reduced integration shell elements with large strain formulation. The concrete core is modeled using eight nodes solid elements as one layer with holes similar to the negative shape, and dimensions of the shear studs embedded in concrete. The shear studs are modeled directly using eight nodes solid elements as one part of head and shank. Since it was assumed that no deformation occurred in the penetrator, it was modeled as an analytical rigid surface. Assembly techniques were used to compose upper plate skin with upper shear connectors and lower plate skin with lower shear connectors. Both assembly of upper plate-upper connectors and lower plate-lower connectors are adjusted such that all shear studs are embedded in its prepared holes in concrete core as shown in Figure (3) and (4). 


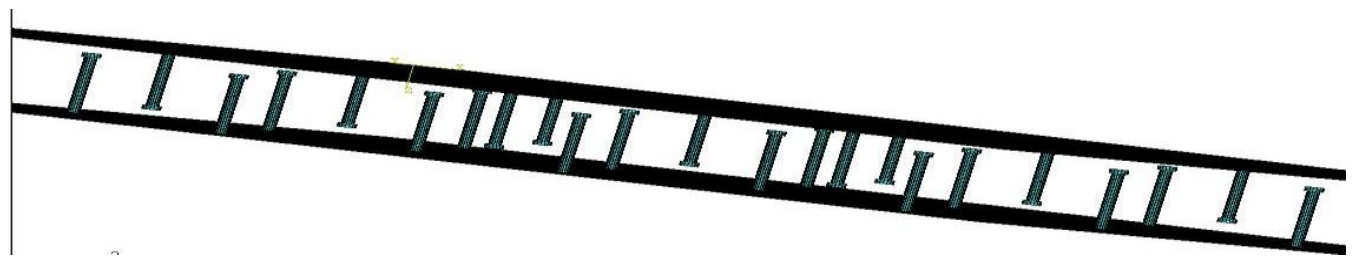

Fig.3. Assembly of skin plates and shear connectors

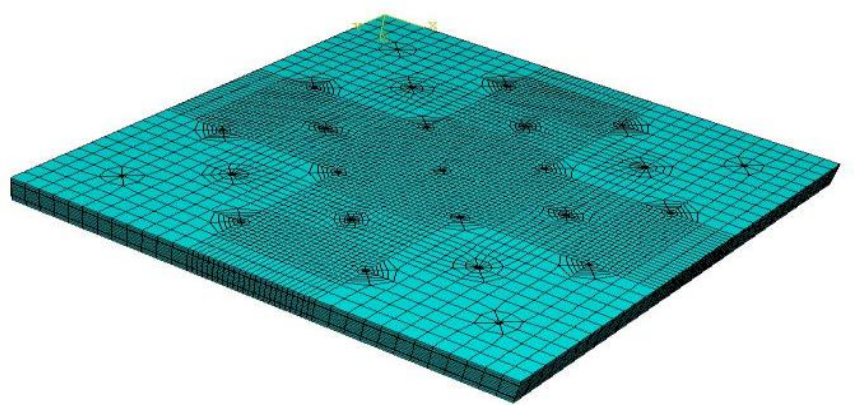

Fig.4. Meshing of concrete core

Concrete core are imported between steel plates, while analytical rigid part (indenter) are adjusted in the center of upper steel plate. Meshing is not requires for the analytical rigid element representing the indenter in the model. The steel plates were divided into regions of different mesh size, such that the mesh in the middle of shell were refined by mesh size $(16 \times 16 \mathrm{~mm})$, while rest of shell was meshed by size $(25 \times 25 \mathrm{~mm})$. The shear connectors (studs) are meshed by a refined mesh of approximate element side size $(2.5 \mathrm{~mm})$. The concrete core is meshed also into regions of different mesh size, such that the mesh in the middle of the core was refined by the mesh size used for steel plates. Regions of stud holes were of approximate element side size of (2.5 mm), as shown in Figures (5).

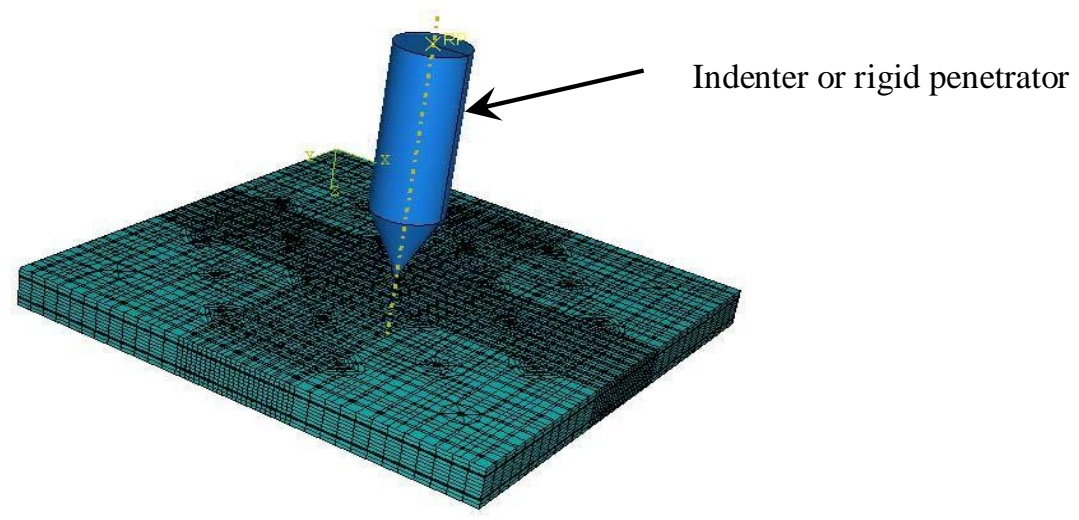

Fig.5. Assembly of indenter with DSC slab

\subsubsection{Material modeling}

Steel is assumed to behave as an elasto-plastic material in both tension and compression. The material properties of steel are specified using elastic and plastic options. The program required input of Young's Modulus and Passion's ratio. The strain hardening effect in steel beyond the yield stress was given in terms of stress and plastic strain, and it was assumed of constant slope. For penetration problems the finite element package provided an option of using failure model by defining shear failure value for used material. The package removes elements -from mesh- that failed when reaching the pre-defined shear failure value and set all stress values for these elements to zero. For steel the shear failure is assumed at value of $80 \%$ of its ultimate stress. Concrete is treated as anisotropic material and stress-strain behavior is taken as shown in Figure (6). 


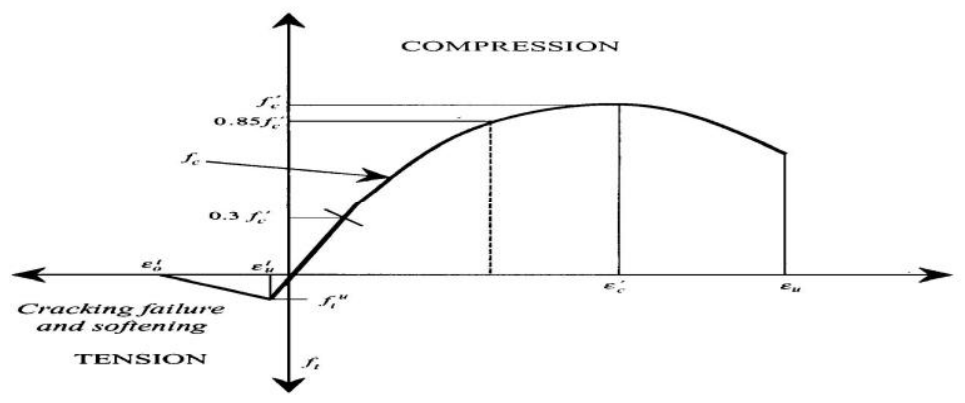

Fig.6. Stress strain behavior of concrete

The curve is assumed linear up to a stress value of $\left(0.3 f_{c}^{l}\right)$, in which $f_{c}^{l}$ is the cylinder strength of concrete in $\mathrm{MPa}$. The strain at which the maximum compressive stress occurred is taken as 0.002 , while the strain, at which the concrete crushed is taken 0.0035. Concrete is assumed to have a maximum stress equal to $\left(0.67 f_{c u}\right)$, where $f_{c u}$ is the cube strength of the concrete as obtained experimentally, and it is approximately equal to $\left(0.853 f_{c}^{l}\right)$. The factor $(0.67)$ accounted for co-relation of cube strength of concrete in bending as mentioned in BS 8110 [9]. For case of penetration in concrete, the shear failure is assumed at value of $40 \%$ of its ultimate stress.

\subsubsection{Loads and boundary conditions}

Boundary conditions are applied on the model to represent the case of clamped upper and lower steel plates. The upper and lower shell edges are prevented from translations and rotations in all directions by applying boundary conditions techniques available in ABAQUS/Explicit on nodes from edge of shell to nodes laying in a distance equal $(70 \mathrm{~mm}$ ) from edge (angle length of upper and lower frames used to clamp steel plates). Reference point of analytical rigid part (indenter) is prevented from moving in all directions except in $\mathrm{z}$ - direction as shown in Figure (7). In modeling of quasi-static test, value equal to (280 $\mathrm{mm}$ ) in z-direction represented load by means of displacement boundary condition on reference point of rigid analytical part (indenter). The output of reaction force and translation of same reference point are obtained. The displacement boundary condition is applied by using amplitude function technique to get the correct reaction force on the reference point of the indenter not a dynamic force. Smooth step function is used to relax the rate of applied displacement similar to quasi-static test.

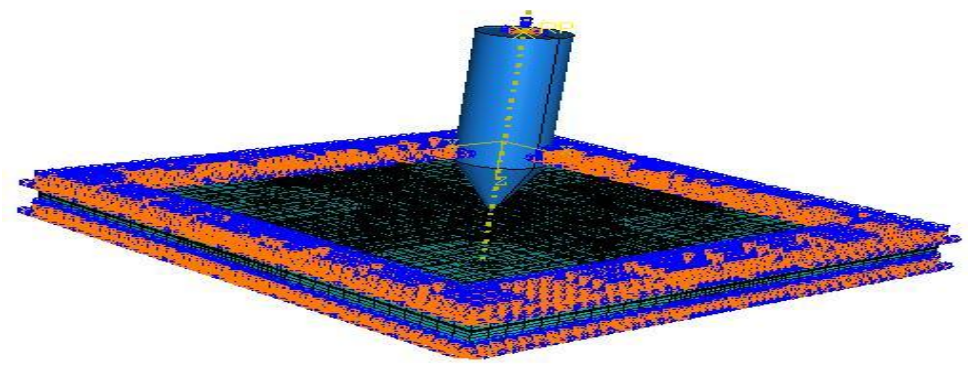

Fig.7. Boundary conditions of the DSC model

\subsubsection{Interaction between elements}

Interactions between elements were important in such models, since many parts composed the panel and different materials were used. To achieve the mentioned interactions in quasi-static problem, master/slave technique was used with two options; surface to surface technique and general contact technique. Interactions between (indenter/whole slab), (upper steel/concrete core) and (lower steel/concrete core) were simulated by surface to surface technique through defining surfaces contained in each part node-set and selecting the pairs of required surfaces of interaction. The surface (node-set) that penetrated another was chosen as master one and the other was the slave. Interaction between upper shear connectors and lower connectors with concrete core was done by general contact technique. Input parameter of contact properties was used to define a coefficient of friction between steel and concrete equal to $(0.3)$. 


\section{Results and Verification of Experimental Work}

Load-displacement plots obtained from finite element analysis for all specimens are compared with corresponding ones obtained from experimental results as shown in Figures $(8,9,10,11,12$ and13). A good agreement between results of experimental work and finite element results were obtained for all specimens. Finite element results showed smaller resistance than those obtained from experiments due to some deviations and differences in material definitions and due to perfect fixation boundary condition considered in the finite element model. This was not completely achieved in experiments by welding of fixations. Therefore the ductility of specimens increased which leads to greater resistance than finite element specimens. Greater ductility of specimens from experimental work results appeared in long total distance traveled by indenter to complete perforation compared with total distance traveled by indenter in model, although reaction force recorded from finite element model showed greater values than experimental values in some regions at same displacement value. This observation lead to not verifying the results by comparing ultimate load as done by N.E Shanmugam et al, but by calculating total absorbed energy from two curves and by approaching the two curves to each other. Table (2) shows comparison of total energy absorbed in both cases.

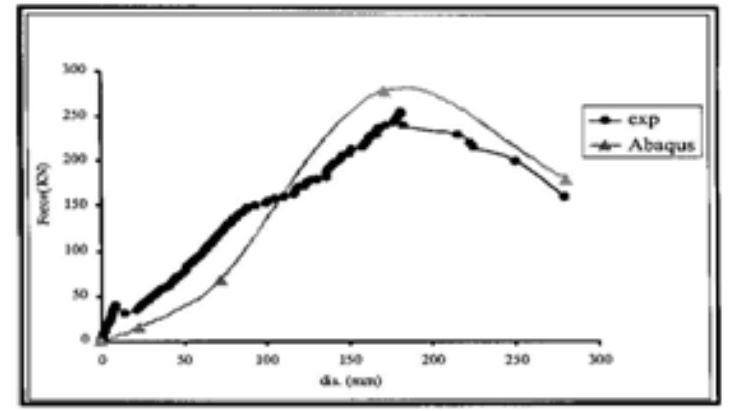

Fig.8. Comparison between finite element and experimental results of pilot test

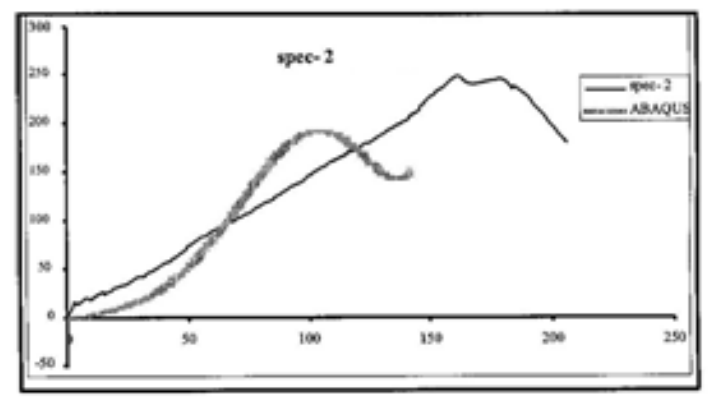

Fig.10. Comparison between finite element and experimental results of DSC2

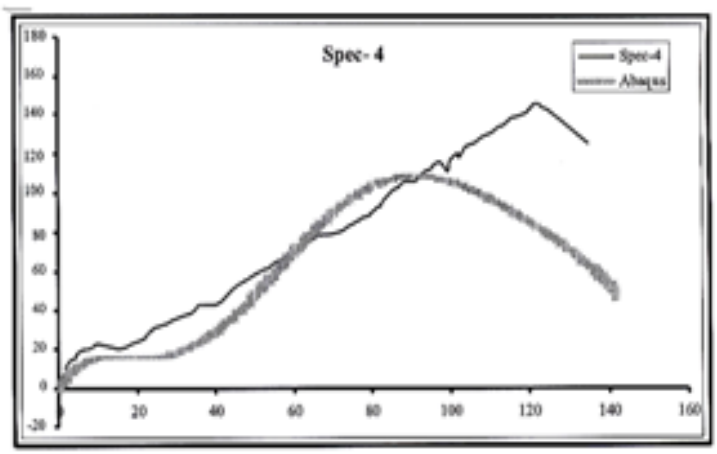

Fig.12. Comparison between finite element and experimental results of $\mathrm{DSC} 4$

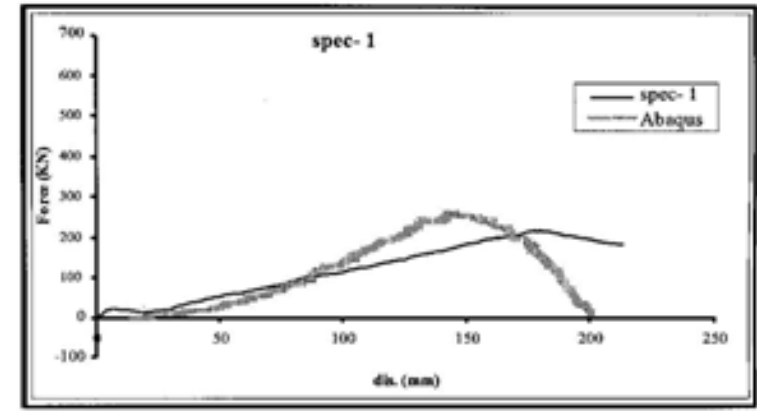

Fig.9. Comparison between finite element and experimental results of DSCl

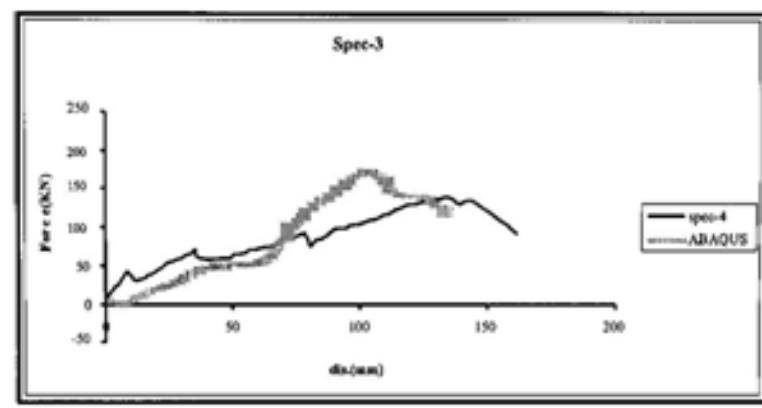

Fig.11. Comparison between finite element and experimental results of $\mathrm{DSC}_{3}$

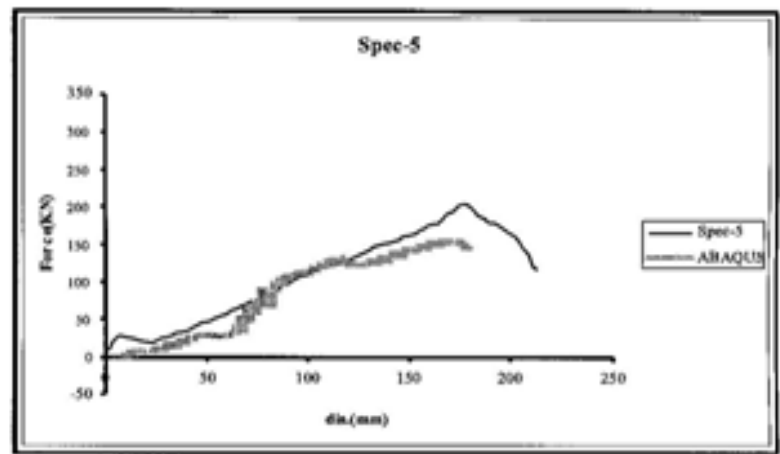

Fig.13. Comparison between finite element and experimental results of DSC5 
Table 2 Comparison of absorbed energy in experiments and ABAQUS model

\begin{tabular}{||l|c|c|c|}
\hline Specimen & $\begin{array}{c}\text { Absorbed Energy in } \\
\text { Experiments }\end{array}$ & $\begin{array}{c}\text { Absorbed Energy in } \\
\text { ABAQUS }\end{array}$ & $\begin{array}{c}\text { Ratio }= \\
\text { Exp. / Abaq. }\end{array}$ \\
\hline Pilot- test & 25.325 ( kJoule) & $23.02($ kJoule $)$ & 1.10 \\
\hline Spec-1 & 20.809 ( kJoule) & $17.30($ kJoule $)$ & 1.202 \\
\hline Spec-2 & 22.824 ( kJoule) & $18.00($ kJoule $)$ & 1.268 \\
\hline Spec-3 & $11.237($ kJoule) & $10.03($ kJoule $)$ & 1.12 \\
\hline Spec-4 & $16.555($ kJoule) & $13.79($ kJoule $)$ & 1.20 \\
\hline Spec-5 & 19.017 ( kJoule) & $17.44($ kJoule $)$ & 1.09 \\
\hline
\end{tabular}

Another technique of verification was to compare failure pattern obtained from experimental work and finite element model. For normal mild steel plates, skin perforated by indenter with conical nose shape. Petaling shape failure was expected as shown in Figure (14).

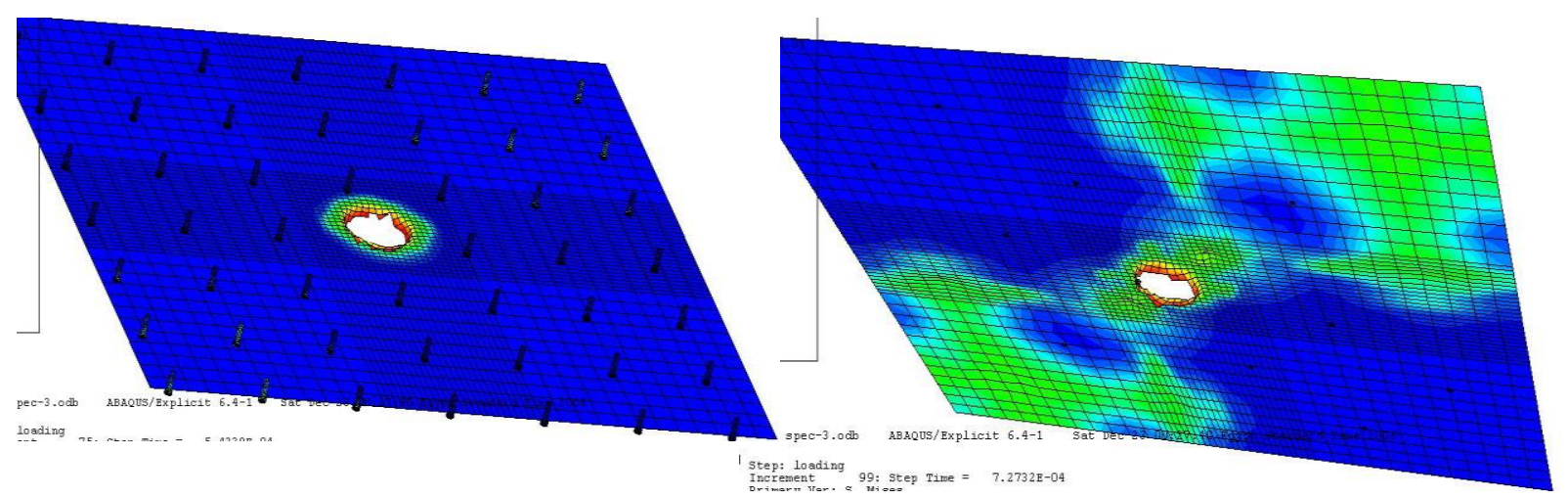

Fig.14. Failure pattern (petaling) of upper and lower steel plates

The width of petaling observed experimentally also verified with petaling width in model as shown in Figure (15). For comparing failure pattern of concrete core, the lower steel skin was cut from specimens after the experiment procedure had finished and cracks were captured to compare with those obtained from finite element model. Diagonal cracks due shear failure were expected, since all specimens were of square shape. A good agreement between two results was observed as shown in Figure (16)
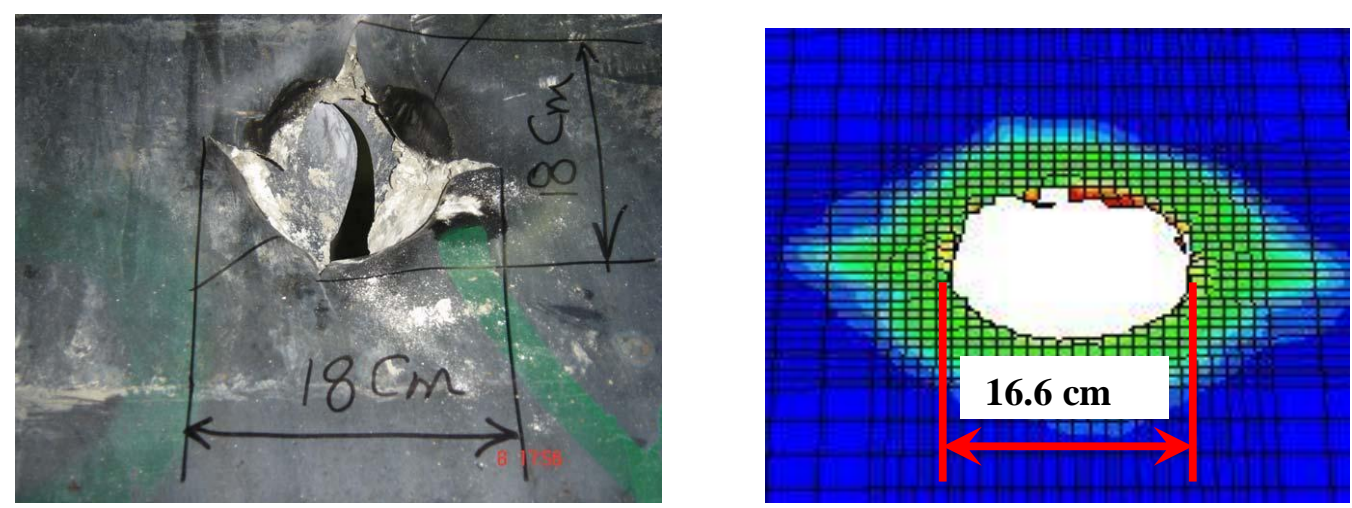

Fig.15. Comparison of Petaling width in experiments and ABAQUS for spec-3 

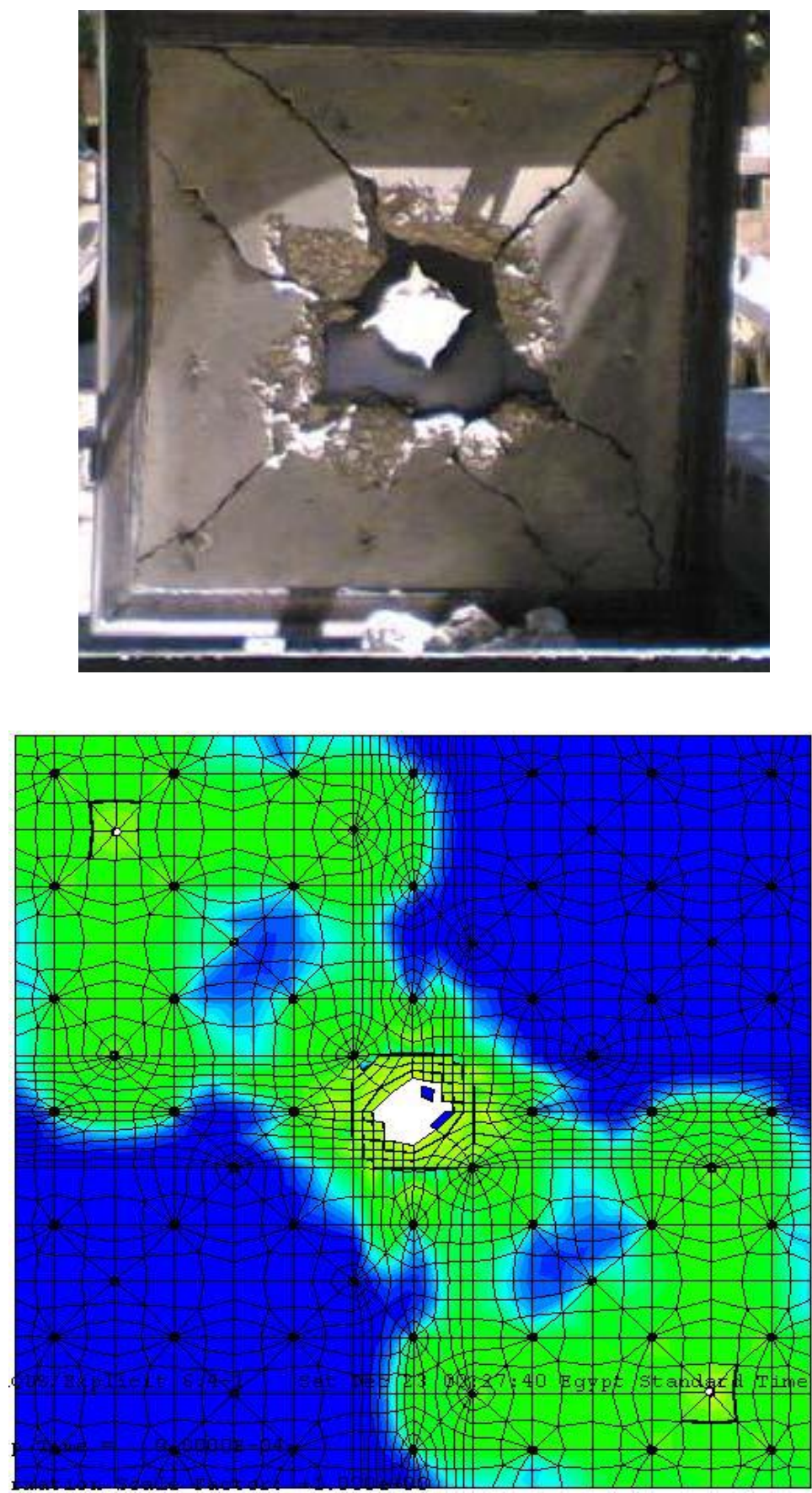

Fig.16. Failure pattern comparison of concrete core in experiments and ABAQUS for spec-3

\section{Discussion of Quasi-static Failure Pattern}

Results of finite element model clarified failure steps of DSC panels during indenter perforation. The roles of upper plate skin, lower plate skin, concrete core, upper shear studs and lower shear studs were observed. In this section, numerical model gave more explanations for the process of perforation by dealing with each panel element independently. General observations were taken from specimen (pilot-test). In this specimen no specified parameter was examined, but it was used for investigating the role of all elements composing the panel, regardless of its effect as a parameter. As indenter started to move, the slab started to 
slightly deflect as one unit. All stress contours observed during this phase were plotted in upper studs, in bases of lower studs and in lower studs' holes in concrete. Plotted stress in upper studs were due to horizontal forces initiated by relative difference in strain between upper steel skin and concrete core, but with small values. Small stress values were also plotted in upper steel skin as shown in Figure (17).

Great stress values were plotted in bases of lower studs as shown in Figure (18), which meant that welding places were stressed from first step of loading, because lower studs played its role as vertical links for lower steel skin which carried the own weight of concrete core. Since lower studs acted as links for lower steel skin to resist deflection and it had anchorage length in concrete, studs holes in concrete widely were affected by great values of stress at same loading step.

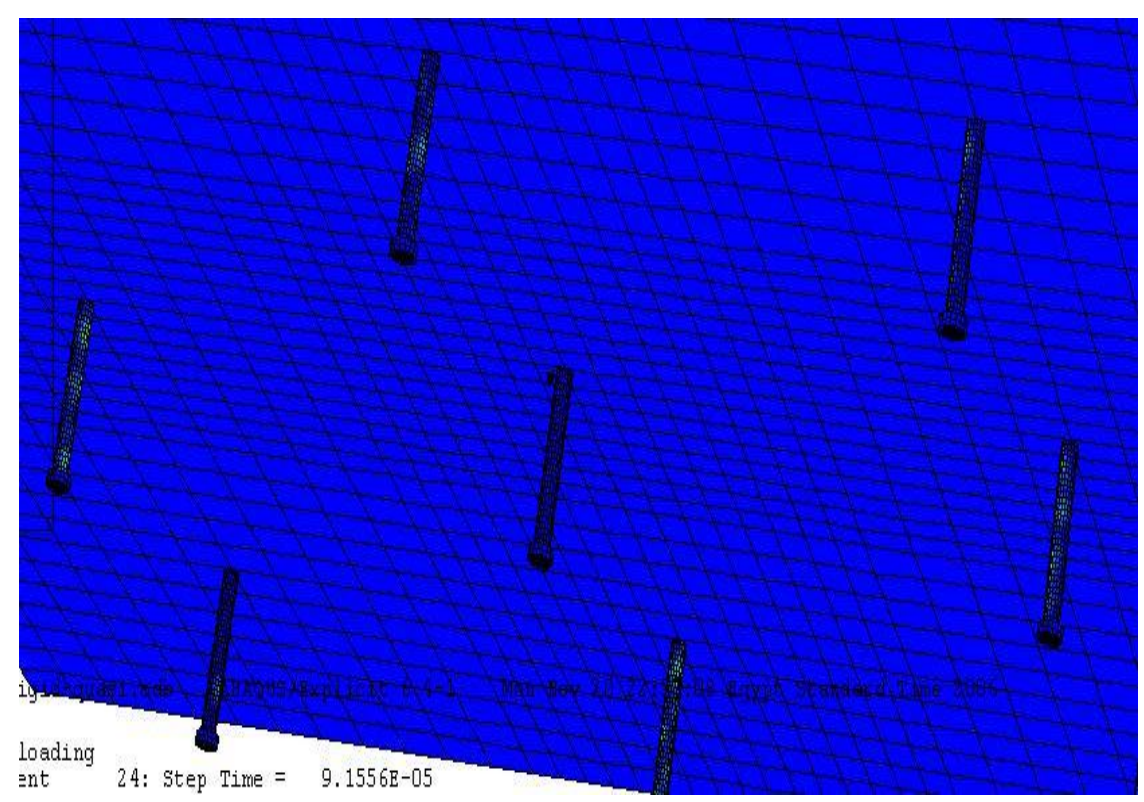

Fig.17. Plotted Von Mises stress in upper studs before perforation of upper steel skin

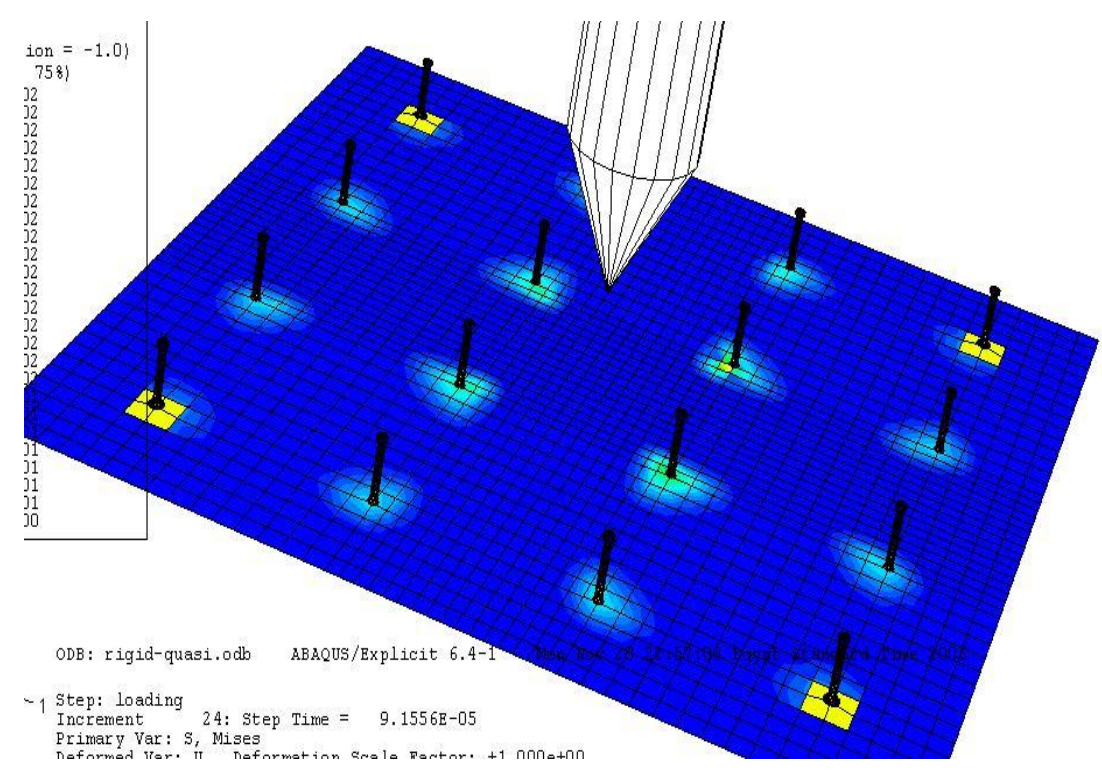

Fig.18. Plotted Von Mises stress in lower studs and lower steel skin at first step of loading 
Big stress values were plotted in holes of studs near to middle of lower plate, where great resistance of great deflection happened, as shown in Figure (19). Due to this resistance of deflection occurred by lower studs, the recorded deflection of middle of lower plate was semi-zero and started to increase after crushing of studs holes in concrete, as shown in Figure (20).

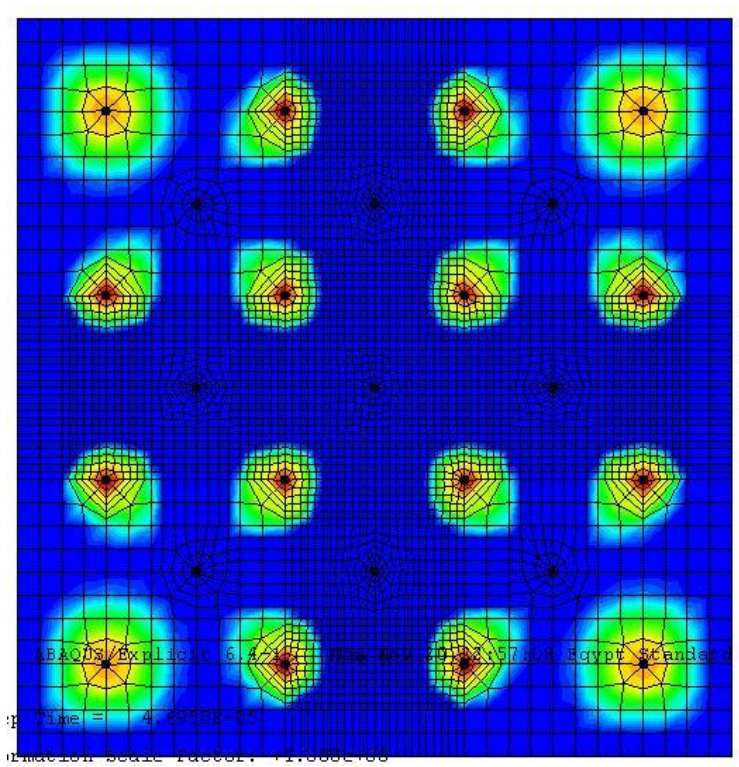

Fig.19. Plotted Von Mises stress in lower studs places in concrete lower fiber at first step loading

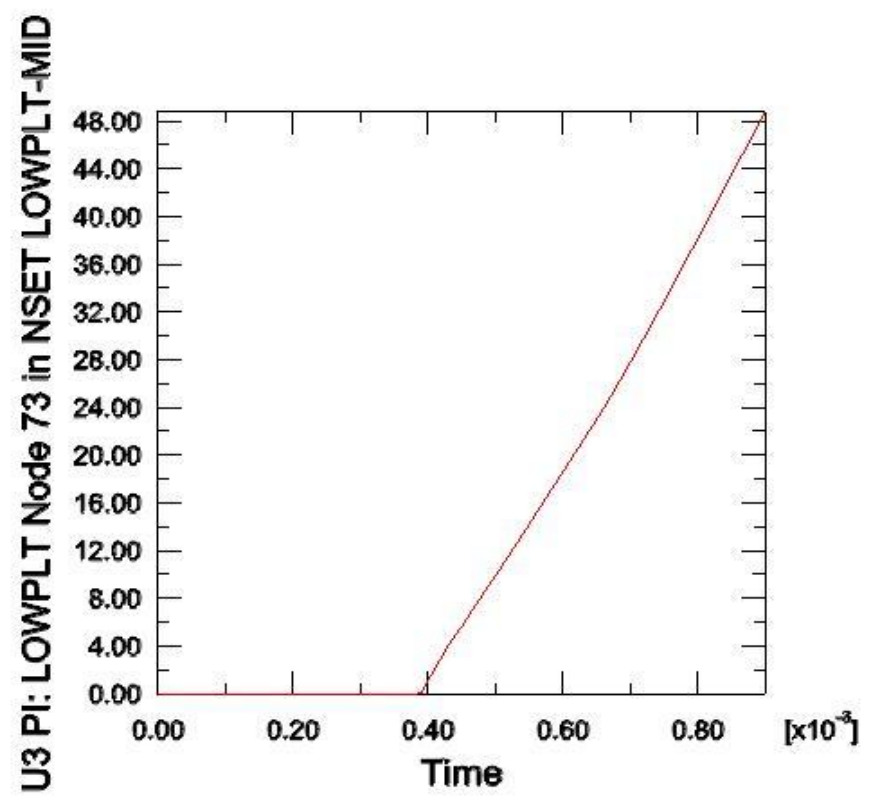

Fig.20. Displacement-time history of middle point of lower steel skin 
As the displacement of indenter increased, reaction forces increased till complete perforation of upper steel skin. At this phase plotted stress at upper plate was equal to maximum stress capacity of steel material predefined in the model inputs. Once perforation had occurred, no stress was plotted in upper studs as shown in Figure (21).

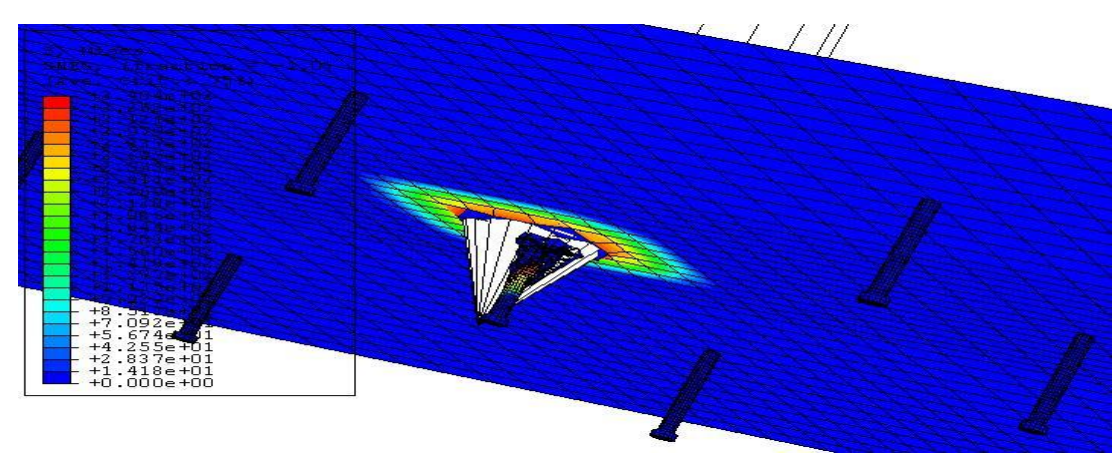

\section{Fig.21. Plotted stress for upper steel skin and upper studs after perforation of upper plate}

By increasing the depth of penetration of indenter in concrete caused failure in elements that reached its predefined shear failure. The crack propagation due to penetration of concrete core was observed, as shown in Figure (22). When indenter perforated total depth of concrete core, localized stress appeared around indenter in lower steel plate with excessive increase in stress in bases of lower studs, which caused failure in lower elements of studs. That meant failure in welding of lower studs as shown in Figure (23) and lower plate lost resistance of supporting vertical links (lower studs) and was completely supported by edged support only. Both base elements of lower studs and its places on lower plate were heavily stressed, but weakness of welding (based element of studs) compared to tensile capacity of lower plate lead to failure in welding not in plate. Interaction between lower steel plate and lower shear studs was done by defining lower steel plate as master surface and defining lower studs as slave surface to permit failure in elements of lower studs not in steel plate elements, as failure of welding was previously expected and we were interested to study failure in welding based on previous work of M. Xie et al [5]. All remaining specimens (spec-1 to spec-5) had the same behavior of failure mechanism during penetration with slight difference from specimen to another according to the parameter that changed to investigate its role in resistance.

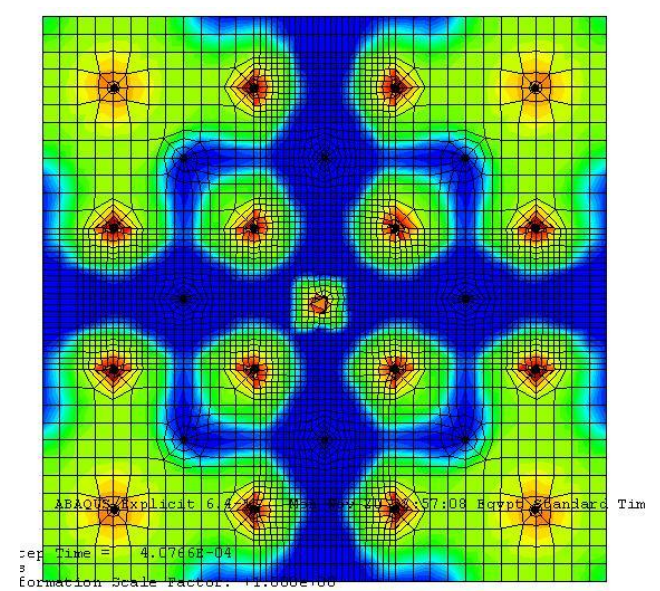

Fig.22. Plotted stress for concrete just before perforation 


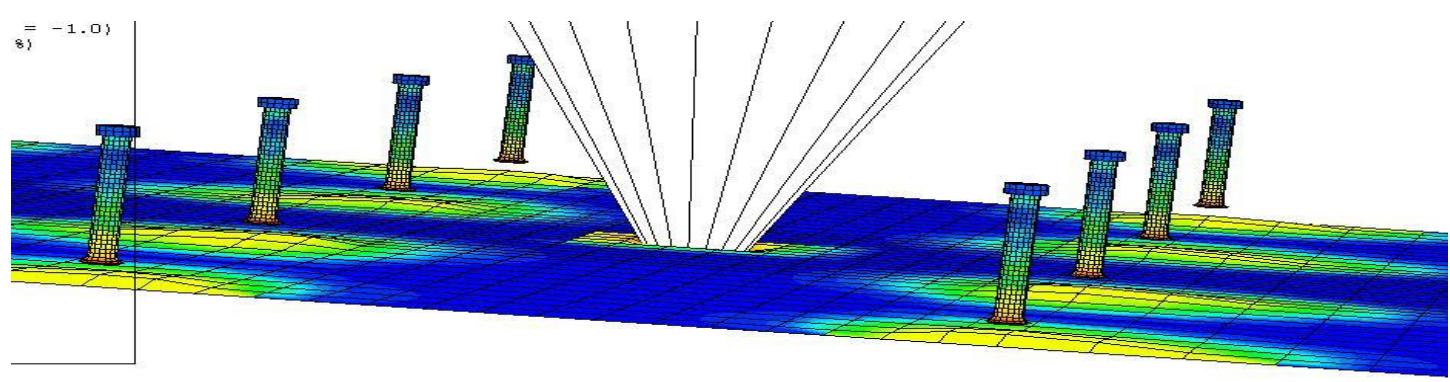

Fig.22. Failure of base elements of lower studs

\section{Conclusions}

The following conclusions can be drawn.

1- Upper plate skin is representing excellent solution for problem of front face spalling, in concrete panels when subjected to impact loading, in addition to its stiffness privilege.

2- Effect of increasing upper plate thickness to face impact loading is very dominated and does not participate with valuable amount of energy absorbed compared with its stiffness increasing.

3- Effect of increasing lower plate thickness to face impact loading has a great and main role in controlling the amount of energy absorbed by such structures due to its ability to prevent concrete scabbing from impact rear face. This relaxes strain rate of concrete while resisting penetration due to presence of lower shear studs.

4- Energy which was absorbed by double skin composite panels can be much greater when lower plate stiffness increased.

The results of the model in this study were very close to the results of their previous experimental tests except in some specimens, the reason was the absence of buckling for steel plates in the model.

\section{References}

[1] Wright, H.D., Oduyemi, T.O.S and Evans, H.R. "The experimental behavior of double skin composite elements ", J. of constructional steel researches, No.19, pp 97-110, (1991).

[2] Wright, H.D, Oduyemi, T.O.S and Evans, H.R. "The design of double skin composite elements", Journal of constructional steel researches, No. 19, pp 111-132, (1991).

[3] Kennedy, R. P., "A review of the procedures for the analysis and design of concrete structures to resist missile impact effects ", J. of Nuclear Engineering and Design, No. 37, pp 183-203, (1976).

[4] Yam, L.C.P. and Chapman, J.C., "The inelastic behavior of simply supported composite beams of steel and concrete", Proc. Of ICE, No. 41, pp 651-684, (1986)

[5] Mckinely, B. and Boswell, L.F. "Behavior of double skin composite construction.", J. of constructional steel researches, No 58, pp1347-1359, (2002).

[6] Shanmugam, N. E., Ghanshyam Kumar and Thevendran,V., "Finite element modeling of double skin composite slabs", Journal of finite element in analysis and design, No.38, pp 579-599, (2002).

[7] Xie, M., Foundoukos, N. and Chapman, J.C., "Experimental and numerical investigation on the shear behavior of friction welded bar-plate connections embedded in concrete", J. of constructional steel research, vol. 61, No. 5, pp625-649, (2005).

[8] Mohamadien, A.R., Agour, A.A., Omer, A.A. and Yones, M.M." Quasi static indentation of double skin composite panels", 12th International Conference on Aerospace Sciences \& Aviation Technology, MTC, Egypt, pp 1-12, (2007)

[9] British Standard Institution, Structural use of concrete, BS 8110: part I, London, 1997. 